\title{
Underlying Beliefs Influencing Vietnamese Nurses and Doctors in Screening for Victims of Domestic Violence: An Exploratory Study
}

\author{
Huong Thi Thanh Nguyen",2*, Debra J. Anderson', Michael P. Dunne3, \\ Huong Thanh Nguyen ${ }^{4}$ \\ ${ }^{1}$ School of Nursing, Queensland University of Technology, Brisbane, Australia \\ ${ }^{2}$ Faculty of Nursing and Midwifery, Hanoi Medical University, Hanoi, Vietnam \\ ${ }^{3}$ School of Public Health \& Social Work, Queensland University of Technology, Brisbane, Australia \\ ${ }^{4}$ Hanoi School of Public Health, Hanoi, Vietnam \\ Email: huongdhy@yahoo.com
}

Received 17 January 2014; revised 25 February 2014; accepted 2 March 2014

Copyright (C) 2014 by authors and Scientific Research Publishing Inc.

This work is licensed under the Creative Commons Attribution International License (CC BY).

http://creativecommons.org/licenses/by/4.0/

(c) (i) Open Access

\begin{abstract}
Many health professionals in Vietnam have limited knowledge and experience in coordinating care for victims of Domestic Violence (DV). This qualitative study aimed to elicit the beliefs of nurses and doctors that are influencing the care of victims of DV. Data were collected by semistructured interviews with nineteen nurses and doctors. Data were analyzed by content analysis and organized by three main themes; behavioral beliefs, normative beliefs and control beliefs. The outcomes of this study will inform the development of intervention strategies that will enable health professionals to better respond to and manage care for women who experience domestic violence in Vietnam.
\end{abstract}

\section{Keywords}

Doctors; Domestic Violence; Nurses; Qualitative Study; Responses; Underlying Beliefs

\section{Introduction}

Domestic violence (DV) against women is a major international human rights and public health issue, and occurs through all levels of society regardless of age, race, religion, wealth or country of origin [1] [2]. Research, which has mainly been undertaken in Western countries, has estimated that between $10 \%$ and $60 \%$ of women

\footnotetext{
${ }^{*}$ Corresponding author.

How to cite this paper: Nguyen, H.T.T., et al. (2014) Underlying Beliefs Influencing Vietnamese Nurses and Doctors in Screening for Victims of Domestic Violence: An Exploratory Study. Health, 6, 691-698.

http://dx.doi.org/10.4236/health.2014.68090
} 
have been hit or exposed to physical assault by a partner at least at one point in their lifetime [1], and 3\% to 52\% of women report having experienced some form of domestic-related physical violence in the previous year [3]. Not only its prevalence, but also its consequences, contributes to DV being a significant public health issue. DV has the potential to have a major impact on women's mental and physical health, including short (e.g. injuries) and long-term (e.g. gastrointestinal disorders, chronic pain syndromes, depression) impacts on their wellbeing [1] [2] [4].

Domestic violence against women is a significant issue within many families. To date, few studies have been conducted that estimate the prevalence of DV among women in Vietnam, however the available research suggests that more than $30 \%$ of married women have been beaten or exposed to other kinds of physical abuse by their spouse [5]-[7]. The prevalence and forms of violence vary according to social strata and other household characteristics. Vu, et al. [8] reported that, at a district and commune level, verbal violence occurred in $20 \%$ to $50 \%$ and physical violence in $5 \%$ to $20 \%$ of families. Furthermore, this study reported that all forms of violence were less likely to occur in families where couples were equal income earners, and that verbal abuse occurred most frequently in households where the woman was the main income earner.

Vietnam has undergone a rapid social transition in the past two decades. Firstly, it has moved from a planned economy system to a market economy, and has progressed toward greater gender equality [9]. It was only in 2007 that domestic violence against women was recognized in Vietnam at the governmental level, by the passing of a law, "Law prevention and control of domestic violence" [10]. Although this recognition now exists at a governmental level in Vietnam, questions remain about the roles and responsibilities of health care providers and communities in caring for the victims of DV. At a community level, the Vietnam Women's Union staff and local reconciliation groups have a mediation role in DV cases. However, the reality is that the subject of DV is largely surrounded by silence in Vietnam. Health providers lack the understanding about violence against women being a serious health concern, and are often reluctant to intervene [11].

As front line healthcare providers, it is very important that nurses and doctors need to screen for exposure to DV. Health professionals should take the responsibility for raising the issue with individual patients, monitoring the cases, expanding the information, and assisting in enhancing skills and awareness among local authorities and others involved [1] [11]. However, there is still a gap in the literature about the role of Vietnamese nurses and doctors in identification of the victims. To date, no known study in Vietnam has explored the psychological factors contributing to the reluctance of nurses and doctors to identify victims of DV. Therefore, the current study aimed to explore the underlying beliefs that influence nurses and doctors in screening for victims of DV. This knowledge will contribute to the design of an intervention to achieve better healthcare of victims of DV in Vietnam.

\section{Method}

\subsection{Research Design}

This was an elicitation study which used the Theory of Planned Behaviour framework [12] as the basis for the guiding of questions to elicit the salient beliefs regarding the role of identification of abused women among health professionals.

\subsection{Ethics}

Ethical approval was obtained from the Queensland University of Technology's Ethics Committee (No: 1000000975), Australia and the Local Ethics Committee, Hanoi School of Public Health (No: 045/2010/TYCCHD3). Approval to conduct the study was obtained from the Managers of the two hospitals where the data was collected.

\subsection{Selection of Hospitals}

This study was conducted in the emergency and outpatient units of two district hospitals in Vietnam. The hospitals were located in two different provinces that have different socioeconomic profiles; one being located in about 5 kilometres from a metropolitan centre, and other being approximately 25 kilometres from a metropolitan centre. 


\subsection{Participant Recruitment}

Nurses and doctors who were working in emergency and outpatient units of the two selected hospitals were asked to participate. Emergency units were selected for participation in this study as there is evidence that the prevalence of DV is likely to be higher among emergency department patients than in the general population (Olive, 2007). Due to the principle of patient classification applied in Vietnamese hospitals, patients with nonurgent health problems (e.g. depression) are required to enter outpatient units. Therefore, outpatient units were also included in this study.

The inclusion criteria for nurses and doctors were:

- Officially employed to work in emergency or outpatient units;

- Involved in the provision of care for the hospital patients.

To recruit participants to the study the researcher contacted the managers of the two hospitals to describe the project and to obtain Letters of Acceptance. Afterwards, the managers introduced the researcher to the staff of the emergency and outpatient units. The researcher then explained the aims of the research and provided staff with a participant information sheet and consent form. Participants were required to sign the consent form prior to participating in the interview.

The researcher returned to the hospitals one week after the first recruitment contact with nurses and doctors to conduct the interviews. The participants could choose a convenient time for them to arrange their individual interview appointment. Each interview was of 20 - 30 minutes duration. All the interviews were conducted in a private room, with discussion being only between the researcher and the participant.

\subsection{Data Collection Instrument}

A series of open-ended questions, were used to elicit the underlying beliefs that influence healthcare provider's identification of victims of DV (Table 1). Firstly, participants were asked about the advantages and disadvantages of screening for victims of DV: "As a nurse/doctor, what do you believe are the advantages/disadvantages of the identification of DV?" The notion of the identification of DV was clarified with all participants to include screening and questioning for DV. Participants were questioned in the interview to ensure they understood the concept of identification.

Participants were then asked to provide their opinions on any individuals or groups who may approve or disapprove of them identifying victims of DV: "Are there any individual or groups who would approve/disapprove of your identification, for screening and questioning?” Participants were also asked about the factors or circumstances that would prevent or encourage them to identify victims of DV: "What factors or circumstances would enable/make it difficult for you to identify the victim?”

\subsection{Transcription and Analyses}

Content analysis was used to analyse the data. All the audio-taped interviews were firstly transcribed verbatim, including any nonverbal or background sounds (e.g., laughter, sighs). Identifying information of all participants was removed. Transcripts of the interviews stored in word files were then content coded using objective analytical codes derived from the TPB and the research question. This included the content analysis (1) of behavioural advantages/disadvantages, (2) of individual or social groups who serve as social referents, and (3) of easy/difficult circumstances to perform the behaviours were applied to reveal belief themes. Only themes which were

Table 1. The semi-structured interview questions. (Q: question).

Q 1 As a nurse/ doctor, what do you believe are the advantages of identification of victims of DV?

Q 2 As a nurse/ doctor, what do you believe are the disadvantages of identification of victims of DV?

Q 3 Are there any individual or groups who would approve of your identification of victims of DV?

Q 4 Are there any individual or groups who would disapprove of your identification of victims of DV?

Q 5 What factors or circumstances would enable you to identify victims of DV?

Q 6 What factors or circumstances would make it difficult or impossible for you to identify victims of DV? 
endorsed by at least $10 \%$ of respondents were then categorized into three main components of the TPB: behavioural beliefs, normative beliefs and control beliefs [12].

Validity was maintained by including independently in undertaking the content analysis. Any differences that emerged were discussed until agreement was established to create a final set of coding categories and to phrase the categories.

\section{Results}

Twenty interviews were conducted among health professionals in the two hospitals (eleven nurses and nine doctors). One interview with a nurse was excluded as the respondent appeared not to understand the interview topic and little information emerged. Therefore, the analytic sample comprised of ten nurses and nine doctors. Table 2 displays the demographic characteristics of the sample. Females represented $68.4 \%$ and the percentage for males was 31.6. The age range was between 18 and 60 (Mean $=35.95$, SD $=9.5$ ). Six of the participants were undertaking managerial roles (in addition to their clinical roles) in the hospital, including two chief nurses and four directors of the units (directors of the units are all doctors).

\subsection{Behavioural Beliefs}

\subsubsection{Facilitate Care Provision}

Participants believed care provision would be facilitated for the abused patients if health professionals could identify a woman being abused. Health professionals felt that the doctor needs to aware about DV in patients in order to make accurate diagnosis. Nurses also identified the importance of knowing about any DV that their patients were experiencing in order to provide specific and related care and referrals for the women. Participant responses reflected this theme:

"if we know about the causes of the injury, it will help to find out the best way to take care of the patients, even it can help us to find out other injuries".

\subsubsection{Provide the Victim a Sympathetic Ear}

Many nurses and doctors thought that one of the good things related to identification is they can provide the vic-

\section{Table 2. Characteristics of the participants.}

\begin{tabular}{|c|c|c|c|}
\hline & & Frequency $(\mathrm{N})$ & Percent (\%) \\
\hline \multirow{2}{*}{ Hospital } & 1 & 10 & 52.6 \\
\hline & 2 & 9 & 47.4 \\
\hline \multirow{2}{*}{ Gender } & Female & 13 & 68.4 \\
\hline & Male & 6 & 31.6 \\
\hline \multirow{2}{*}{ Marital status } & Single & 3 & 15.8 \\
\hline & Married & 16 & 84.2 \\
\hline \multirow{2}{*}{ Occupation } & Nurses & 10 & 52.6 \\
\hline & Doctors & 9 & 47.4 \\
\hline \multirow{4}{*}{ Level of Education } & Postgraduate & 6 & 31.6 \\
\hline & University & 4 & 21.1 \\
\hline & Colleague & 1 & 5.3 \\
\hline & Vocational school & 8 & 41.1 \\
\hline \multirow{2}{*}{ Working position } & Clinical Staff & 13 & 68.4 \\
\hline & Staff undertaking a managerial and clinical task & 6 & 31.6 \\
\hline & & Mean & SD \\
\hline & Age & 35.95 & 9.5 \\
\hline & Working experience (years) & 12.32 & 8.7 \\
\hline
\end{tabular}


tim with a sympathetic ear. Participants stressed that patients, especially women who experience DV, may need someone to listen to them. Health professionals would have an opportunity to listen to the women that could help the women to overcome and work with the hardest moment of the violence. For instance, one nurse said that:

"When we ask her, she can tell me something that helps her to release the stress, good for her to have someone to share".

\subsubsection{Feeling of Doing Something Positive}

It was believed that the health professionals will have a feeling of doing something positive if they identify the victim. A participant said that:

"If I can do something for her, although it may not help her much, I at least feel happy".

Besides benefits, health professionals also revealed some negative consequences which could be associated with their identification of the victims of DV.

\subsubsection{Reactions from the Husband and His Family Members}

Most of participants agreed that a drawback of identification of the victim is that they may receive negative reactions from the husband and his family members. Health professionals worried that the violence may suddenly turn to them as the husband was absolutely furious at the responses of nurses or doctors to help his wife. The following extract was typical of participant's concerns about the potential harm:

"I just worry that the husband may get angry, he is the abuser and of course he does not want anyone to know about his mistake, his family also takes sides with him surely, they even abuse staff in the hospital if they cannot control themselves".

\subsubsection{Meddle with Victim's Private Issues}

Another factor that may limit the health workers to screen for DV is the feeling that they will meddle with victim's private issues. Some health professionals believed that when a person visits a hospital, she just want to search for health care services. The women may feel shameful to expose that she is a victim of DV. She may need the help from her parents or relatives rather than the help from a nurse or a doctor. A nurse stated that:

"It is a very sensitive matter of their family; they may not want strange people to be involved in, if we ask them, the situation may be worse".

\subsection{Normative Beliefs}

\subsubsection{Compassionate People}

Compassionate people were the first referent who would approve health professionals' identification of the abused women. Health professionals believed that helping an abused woman is a good thing to do. They believe that people who understand the importance of helping an abused woman would certainly expect health professionals to screen for the violence with their patients. As one participant commented:

"When a woman is abused, everybody will feel sorry for her so they will approve absolutely if I support her".

\subsubsection{The Victim and Her Family}

Health professionals believed that the victim and her family would approve of them detecting violence occurring with women. They stated that although some women may try to hide the fact that they are victim of DV, it was always important for a nurse or a doctor to listen to and to help the women to overcome the violence. They believed that the women would never refuse the help of health professionals if it was done in a sensitive way. One participant explained:

"The women would want someone to know about her trouble and help her, her family also want good things for her”.

\subsubsection{Health Professionals' Family and Colleagues}

Health professionals believed that their family and colleagues are also people who may approve of health professionals responding to victims of DV. Nurses and doctors believed that their family always stayed behind them and emotionally supported them in whatever they do to help their patients. They also believed that most people 
who were trained to be a healthcare provider would have a warm heart; therefore they believed in their colleagues to understand the importance of helping abused women. A participant expressed that:

"If I talk with either my colleagues or my family, they will understand and support me if I help the women".

\subsubsection{The Victim's Husband and His Family}

The health professionals believed that the victim's husband and his family would disapprove of health professionals screening for DV. Health workers believed that any response taken by health workers would benefit the victim and potentially disadvantage the husband. A participant expressed their concern:

"The abuser will never accept any responses of a nurse or a doctor to his violence at home".

\subsection{Control Beliefs}

\subsubsection{Current Hospital Facilities Are Good}

Many nurses and doctors believed that their hospital's conditions are the best place to screening for DV. Good support facilities would help doctors to assess injuries of the women. For example, a participant said that:

"My hospital has quite enough essential facilities to identify the injuries of the victim...we have $x$-ray, ultrasound..."

\subsubsection{Support of Colleagues}

Health workers reported that if a case of DV presents, their colleagues will support them in their work and they will have time for the victim. A respondent said that:

"We help each other in work. If a woman just wants to keep talking with me about her violence at home, because she needs someone to share, yes, my colleague will help me with other clinical tasks, I think that".

\subsubsection{Being a Health Worker}

It was also felt that the position of a health worker is an advantage, as during the health examination, nurses and doctors can ask about the causes of the injuries and the victim can feel comfortable about sharing information about their situation. A doctor explained:

"They may not tell the truth with others, but with doctors, they seem to be more honest because we bring them the health".

\subsubsection{Work Experience}

Many respondents believed that their work experience makes it easier for them to identify the victims. Health professionals believed that work experience could help them to distinguish injuries caused by DV from injuries caused by other accidents. The attitudes of the women they believed may be an indication of DV exposure that an experienced health professional can recognize. As one participant with many years experience noted:

"She said that she fall of her bicycle, but with her back eye, my experience told me that she was hit by someone".

\subsubsection{Availability of Time}

A condition that health workers believed prevented them from identifying abused women was the availability of time. Most respondents said that if they had the time they would be more likely to identify victims of DV. Most of health professionals believed that the busyness of their work and severe physical conditions of patients was an impediment to providing appropriate care. For instance, a doctor said that:

"In the day shift it may be fine. In the night shift, many emergency patients but only one doctor in charge, so you know, how can I cover all of them, some patients they have an accident for example, it may damage his life".

\subsubsection{Willingness of the Victim}

Health workers also believed that the willingness of the victim to reveal their situation influences the appropriate responses that health workers can provide. Nurses and doctors stated that even when they suspect an abuse case, they may ignore it if the patient herself and her family member do not want to share information about their difficulty. They justified their response by stating that they believed that DV is considered as a private matter so if the victim does not want others to be involved, then health workers should not interfere. Some of the health workers also believed that their main task is looking after health related to problems such as injuries to the victim's body. Some nurses and doctors also felt that it would be easier for them to screen for DV if the victim was willing to talk 
with them about the violence. This was demonstrated by the following comments:

"I know clearly she was beaten but she tells lie..."

\subsubsection{Lack of Specialized Facilities}

In addition, it was recognized that there is a lack of specialized facilities. Nurses and doctors believed that there was a lack of guidelines on how to deal with DV and abuse and that they felt that this was a significant barrier to health workers in screening for DV. They also expressed that discussing DV with women is very sensitive, and dismayed that there is no private space in their hospital. A nurse said:

"You see, patient is everywhere, if I ask her about the violence, she will cry again, not good if other patients see this patient cries again".

\section{Discussion}

Overall, the beliefs expressed by health professionals in this study contribute to the growing body of literature about barriers and facilitating factors that influence health professional's responses to DV [13]-[16] and is unique to the Vietnam context.

The majority of nurses and doctors expressed the importance of responding and identifying victims of DV, and exhibit compassionated attitudes towards the women. This finding is consistent with previous research [17] which identified that most health providers have compassionate attitudes toward the abused women. The health professionals in this study also felt that they could not communicate their compassion effectively due to barriers including time and lack of personal space. The study also found that health care workers may recognize the presence of DV in their practice, however may not be fully aware of the magnitude of the problem due to these barriers. Both training and professional experience may help to increase the readiness of the staff to be more proactive about its identification and management [11] [13] [14] [18].

This study also identifies negative beliefs which may be barriers to nurses and doctors in screening for victims of DV. Previous studies support these findings which show that health professionals carefully consider the consequences of asking about DV, the safety of health staff and also the potential disruption that intervention may cause in the victim's life [11] [13].

While participants identified a number of individuals or groups who they believed would approve of health staff detecting victims of DV, they believed that the victim's husband and his family would be disapproving of their intervention. Health professionals believed that one of disadvantages of screening for DV is a potential negative reaction from the abuser, Previous studies have found that households that have experienced DV may also object to health staff initiating any interventions because DV is often considered a private family matter [19].

Nurses and doctors identified the belief that there were advantages of working in the hospital environment that would facilitate them screening for victims of DV. These finding are supported by a study by Gurmanis [13], who found that professional support (including support from colleagues) and the availability of facilities at the hospital were positive factors contributing to health professional's motivation to intervene in cases of DV. This study also found that nurses and doctors lack sufficient skills to assist them in intervening [11] [13] [18] [20].

\section{Implication}

This is the first study to examine the beliefs of health professionals regarding responding to victims of DV conducted in Vietnam. The findings of this study have potential to meaningfully contribute to the knowledge of DV and its management in Vietnam. By understanding underlying beliefs that influence health professionals’ identification of victims of DV, it is recommended that hospitals discuss strategies which they feel could help to facilitate their staff to perform this task and also help staff to deal with the relationship between the victims and their families. An expectation for each hospital could be that guidelines for nurses and doctors to follow, and establishment of a comfortable and private environment for them to work with the women should be provided.

\section{References}

[1] Krug, E.G., Dahlberg, L.L., Mercy, J.A., Zwi, A.B. and Lozano, R. (2002) World Report on Violence and Health. World Health Organization, Geneva.

[2] World Health Organization (2009) Combating Gender-Based Violence in the South-East Asia Region. 
[3] Heise, L., Ellsberg, M. and Gottmoeller, M. (2002) A Global Overview of Gender-Based Violence. International Journal of Gynecology \& Obstetrics, 78, S5-S14. http://dx.doi.org/10.1016/S0020-7292(02)00038-3

[4] Ellsberg, M., Jansen, H.A.F.M., Heise, L., Watts, C.H. and Garcia-Moreno, C. (2008) Intimate Partner Violence and Women's Physical and Mental Health in the WHO Multi-Country Study on Women's Health and Domestic Violence: An Observational Study. The Lancet, 371, 1165-1172. http://dx.doi.org/10.1016/S0140-6736(08)60522-X

[5] Luke, N., Schuler, S.R., Bui, T.T.M., Pham, V.T. and Tran, H.M. (2007) Exploring Couple Attributes and Attitudes and Marital Violence in Vietnam. Violence against Women, 13, 5-12. http://dx.doi.org/10.1177/1077801206295112

[6] Nguyen, T.D. (2006) Prevalence of Male Intimate Partner Abuse in Vietnam. Violence against Women, 12, $732-739$. http://dx.doi.org/10.1177/1077801206291555

[7] Nguyen, D.V., Ostergren, P.O. and Krantz, G. (2009) Intimate Partner Violence against Women, Health Effects and Health Care Seeking in Rural Vietnam. European Journal of Public Health, 19, 178-182. http://dx.doi.org/10.1093/eurpub/ckn136

[8] Vu, M.L., Vu, T.H., Nguyen, H.M. and Clement, J. (2000) 24 April 2010). Gender-Based Violence: The Case of Vietnam. http://siteresources.worldbank.org/INTVIETNAM/Resources/Gender-Based-Violence.pdf

[9] Drummond, L. and Rydstrom, H. (2004) In Gender Practices in Contemporary Vietnam. Singapore University Press, Singapore City.

[10] The National Assembly of Vietnam (2007) Law on Prevention and Control of Domestic Violence.

[11] Krantz, G., Phuong, T.V., Larsson, V., Thuan, N.T.B. and Ringsberg, K.C. (2005) Intimate Partner Violence: Forms, Consequences and Preparedness to Act as Perceived by Healthcare Staff and District and Community Leaders in a Rural District in Northern Vietnam. Public Health, 119, 1048-1055. http://dx.doi.org/10.1016/j.puhe.2005.03.015

[12] Fishbein, M. and Ajzen, I. (1975) Belief, Attitude, Intention and Behaviour: An Introduction to Theory and Research. Addison-Wesley Publishing Co, Inc., Boston.

[13] Gutmanis, I., Beynon, C., Tutty, L., Wathen, C.N. and MacMillan, H. (2007) Factors Influencing Identification of and Response to Intimate Partner Violence: A Survey of Physicians and Nurses. BMC Public Health, 7.

[14] Minsky-Kelly, D., Hamberger, L.K., Pape, A.D. and Wolff, M. (2005) We’ve Had Training, Now What? Qualitative Analysis of Barriers to Domestic Violence Screening and Referral in a Health Care Setting. Journal of Interpersonal Violence, 5.

[15] Protheroe, L., Green, J. and Spiby, H. (2004) An Interview Study of the Impact of Domestic Violence Training on Midwives. Midwifery, 20, 94-103. http://dx.doi.org/10.1016/j.midw.2003.08.001

[16] Stinson, C.K. and Robinson, R. (2006) Intimate Partner Violence: Continuing Education for Registered Nurses. The Journal of Continuing Education in Nursing, 37, 58-62.

[17] Cann, K., Withnell, S., Shakespeare, J., Doll, H. and Thomas, J. (2001) Domestic Violence: A Comparative Survey of Levels of Detection, Knowledge, and Attitudes in Healthcare Workers. Public Health, 115, 89-95.

[18] García-Moreno, C. (2002) Dilemmas and Opportunities for an Appropriate Health-Service Response to Violence Against Women. The Lancet, 359, 1509-1514. http://dx.doi.org/10.1016/S0140-6736(02)08417-9

[19] Wong, T.W., Chung, M.M. and Yiu, J.J. (1997) Attitudes and Beliefs of Emergency Department Doctors towards Domestic Violence in Hong Kong. Emergency Medicine, 9, 113-116. http://dx.doi.org/10.1111/j.1442-2026.1997.tb00366.x

[20] Nguyen, V., Per-Olof, O. and Gunilla, K. (2008) Intimate Partner Violence against Women in Rural Vietnam-Different Socio-Demographic Factors Are Associated with Different Forms of Violence: Need for New Intervention Guidelines? BMC Public Health, 8, 1-11. 